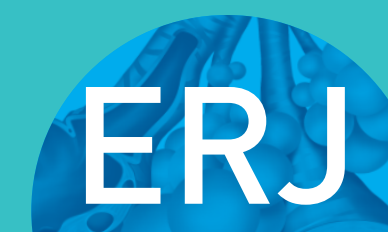

open research
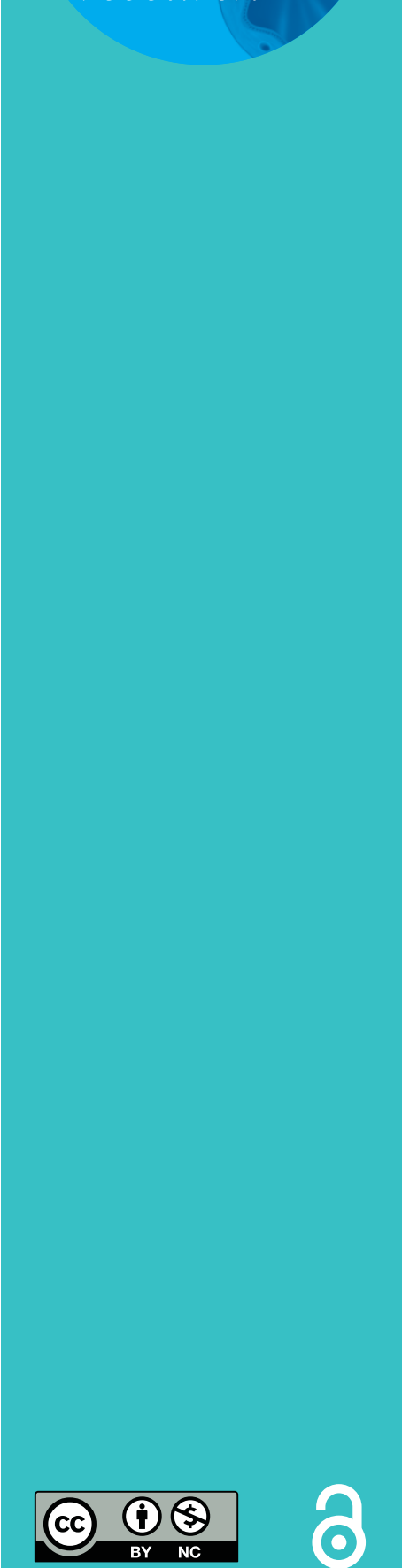

\section{Incidence and predictive factors of lung cancer in patients with idiopathic pulmonary fibrosis}

\author{
Eisuke Kato ${ }^{1}$, Noboru Takayanagi ${ }^{1}$, Yotaro Takaku${ }^{1}$, Naho Kagiyama ${ }^{1}$, \\ Tetsu Kanauchi ${ }^{2}$, Takashi Ishiguro ${ }^{1}$ and Yutaka Sugita ${ }^{1}$
}

Affiliations: 'Dept of Respiratory Medicine, Saitama Cardiovascular and Respiratory Center, Saitama, Japan. ${ }^{2}$ Dept of Radiology, Saitama Cardiovascular and Respiratory Center, Saitama, Japan.

Correspondence: Eisuke Kato, Dept of Respiratory Medicine, Saitama Cardiovascular and Respiratory Center, 1696 Itai, Kumagaya, Saitama 360-0105, Japan. E-mail: eisuke.katodmed.showa-u.ac.jp

ABSTRACT The incidence and risk factors of lung cancer in patients with idiopathic pulmonary fibrosis (IPF) have been poorly investigated.

We conducted a retrospective study of 632 patients with IPF to assess the incidence and risk factors of lung cancer development.

Seventy patients developed lung cancer over a median follow-up period of 3.8 years. The incidence density of lung cancer development was 25.2 cases per 1000 person-years. The most frequent type was squamous cell carcinoma (30\%), the majority developed lung cancer in the peripheral lung (82.9\%) and adjacent to usual interstitial pneumonia (75.7\%). In a multivariate Cox regression hazard model, pack-years of smoking $\geqslant 35$ and coexisting emphysema were associated with lung cancer development. The 1-, 3- and 5-year all-cause mortality rates after lung cancer diagnosis were 53.5\%, 78.6\% and 92.9\%, respectively.

The incidence density of lung cancer is high in IPF patients and occurs more frequently in patients with smoking history of pack-years of smoking $\geqslant 35$ and with coexisting emphysema. The majority of lung cancers develop adjacent to usual interstitial pneumonia. Knowledge of these factors may help direct efforts for early detection of lung cancer and disease management.

@ERSpublications

In patients with IPF, lung cancer will develop in 25.2 cases per 1000 person-years. Clinicians should pay attention to the development of lung cancer, especially in patients with $\geqslant 35$ packyears of smoking and coexisting emphysema. http://ow.ly/KLjx30hObFu

Cite this article as: Kato E, Takayanagi N, Takaku Y, et al. Incidence and predictive factors of lung cancer in patients with idiopathic pulmonary fibrosis. ERJ Open Res 2018; 4: 00111-2016 [https:// doi.org/10.1183/23120541.00111-2016].

Received: Oct 042017 | Accepted after revision: Nov 212017

Conflict of interest: None declared

Copyright $\odot$ ERS 2018. This article is open access and distributed under the terms of the Creative Commons Attribution Non-Commercial Licence 4.0. 


\section{Introduction}

Idiopathic pulmonary fibrosis (IPF) is a specific form of chronic, progressive fibrosing interstitial pneumonia of unknown cause. It is associated with the histopathologic and/or radiologic pattern of usual interstitial pneumonia (UIP) $[1,2]$. Comorbidities including lung cancer (LC), pulmonary hypertension, chronic obstructive pulmonary disease (COPD)/emphysema, pulmonary embolism and pulmonary infections can occur in IPF [1-4]. The identification and prompt treatment of comorbidities may have a clinically significant and meaningful effect on overall outcome for patients with IPF [4].

Several studies have documented that patients with IPF are at high risk for the development of LC [5-9], and in Japan, $11 \%$ of IPF patients died of LC [10]. Thus, there is a striking association between IPF and LC. The prevalence of LC in patients with IPF is reported to be 3-45.7\% [9, 11-17]. However, only a few studies have evaluated the incidence of LC during IPF follow-up [7, 18-20]. OzawA et al. [18] reported the cumulative incidence of and predictive factors for LC in IPF. The 5-year cumulative incidence rate of LC in $103 \mathrm{IPF}$ patients was $15.4 \%$, and age was an independent significant factor predicting the development of LC. In their report, they speculated that coexisting emphysema was possibly associated with the development of LC in IPF patients, and they suggested that further investigations are needed to clarify this possibility. HyldgaARD et al. [19] reported an incidence density of 36 cases per 1000 person-years of LC in 121 patients with IPF. LE JeUne et al. [7] reported an incidence density of 11.2 cases per 1000 person-years of LC in 1064 patients with IPF in a longitudinal computerised healthcare dataset in the UK. TOMASSETTI et al. [20] reported a cumulative incidence of $41 \%$ and $82 \%$, respectively, at 1 and 3 years of LC in 23 patients with LC and IPF, and that patients with LC were more frequently smokers, with combined pulmonary fibrosis and emphysema (52\% versus $32 \%)$ than patients with IPF only $(\mathrm{n}=158)$. Previous studies have reported factors such as smoking, age, gender and emphysema as risk factors for LC in IPF $[11,12,14,15,20]$. However, these risk factors were assessed when IPF patients had already developed LC, with only one exception in OzAWA's study [18], and may not be predictive of the risk of developing LC at the initial diagnosis of IPF. We thus thought that the incidence density of and risk factors for LC development, including emphysema, should be elucidated on a large scale.

\section{Methods}

\section{Subjects}

From January 1995 to July 2011, 910 patients with IPF were treated at our institution. Of these patients, 278 were not included: 223 had simultaneous LC at IPF diagnosis, and 10 patients were diagnosed as having microscopic polyangiitis at IPF diagnosis. The observation period of 45 patients was less than 3 months. Thus, 632 patients comprised the cohort of this study. All patients fulfilled the criteria for IPF of the American Thoracic Society (ATS) and European Respiratory Society (ERS) [2] or the official ATS/ERS/Japanese Respiratory Society/Latin American Thoracic Society statement on IPF [1]. Emphysema was considered present if low-attenuation areas were present on high-resolution computed tomography (HRCT) images. The study was approved by the institutional review board of Saitama Cardiovascular and Respiratory Center.

\section{IPF diagnosis}

Each patient was diagnosed as having IPF according to criteria used at the time of diagnosis. We checked the CT scan of all patients and diagnosed as IPF only those patients who satisfied the diagnostic criteria of 2011 and 2013 [1,2]. All patients were evaluated using HRCT. A radiologist and a respiratory physician used HRCT to diagnose patients with UIP pattern as having IPF, and they did not include possible UIP pattern. Most patients did not undergo surgical lung biopsy.

\section{Emphysema diagnosis}

On CT scan, we defined low-attenuation areas bordered by a very thin $(<1 \mathrm{~mm})$ or no wall in the normal lung as emphysema.

\section{LC diagnosis and histologic type}

LC was diagnosed on the basis of pathology or cytology. When cytological findings were suggesting nonsmall cell LC, but histological type was not specified, LC was diagnosed as unclassified nonsmall cell LC.

\section{Study design}

This was a retrospective cohort study. Clinical, laboratory, radiographic, cytological and pathological data and outcome were collected from medical records. Baseline clinical parameters were obtained within 1 month of initial diagnosis. If these data were not obtained within this period, we considered them to be unknown. Then, during follow-up periods, we investigated the incidence of LC. Survival status was obtained from medical records and/or telephone interviews. We also investigated the risk factors of LC development. 


\section{Statistical analysis}

Categorical baseline characteristics are summarised by frequency and per cent, and continuous characteristics are reported as mean $\pm \mathrm{SD}$ or median and range as appropriate. Group comparisons were made using Wilcoxon rank-sum test, or Fisher's exact test as appropriate. Diagnosis of LC was estimated by Kaplan-Meier analysis. Survival was evaluated using a Kaplan-Meier curve and compared between groups using log-lank tests. Cox regression analysis was used to determine whether the following factors at diagnosis increased the risk of LC: sex, age, body mass index, smoking history, pack-years of smoking, emphysema, forced vital capacity (FVC), forced expiratory volume in $1 \mathrm{~s}$ (FEV1)/FVC ratio, lung diffusion capacity for carbon monoxide, partial pressure of oxygen in arterial blood, erythrocyte sedimentation rate (ESR), C-reactive protein (CRP), serum albumin and Krebs von den Lungen-6 (KL-6) at baseline. In all analyses, a p-value of $<0.05$ was considered to be statistically significant. We conducted all statistical analyses with SAS version 9.2 (SAS Institute, Cary, NC).

\section{Results}

Characteristics of patients who did not develop LC or developed LC during IPF follow-up

Of the 632 patients with IPF, the mean age was 69.5 years, $76.4 \%$ were male, $76.4 \%$ were smokers, and coexisting emphysema was present in 188 (29.7\%) patients. Table 1 compares the clinical and physiological characteristics of the patients with and without LC diagnosis. At baseline, patients who later developed LC were younger, more commonly male and smoking more pack-years of cigarettes, and more frequently had emphysema, and had a better FVC \% and worse FEV1/FVC.

\section{Incidence of LC}

Of the 632 patients with IPF, 70 (11.1\%) developed LC during median (range) follow-up periods of 3.8 (0.25-15.2) years. The 5- and 10-year cumulative LC development rates were $12.2 \%$ and $23.3 \%$, respectively. The incidence densities of LC development in all, male and female patients were 25.2, 30.8 and 6.3 cases per 1000 person-years, respectively (figure 1).

\section{Characteristics of LC}

The mean age at LC diagnosis was 71.7 years. Of the 70 patients who developed LC, 66 (94.3\%) were male, all patients were smokers, coexisting emphysema was present in 42 (60.0\%) patients (table 1), and the histological types of LC in 21 (30.0\%), 14 (20.0\%), 14(20.0\%) and $15(21.4 \%)$ patients were squamous cell carcinoma, adenocarcinoma, small cell carcinoma and unclassified nonsmall cell LC, respectively. The locations of LC were peripheral in 58 patients (82.9\%), lower lobe in 34 (48.6\%) and adjacent to UIP in 53

TABLE 1 Baseline characteristics of patients with idiopathic pulmonary fibrosis with or without lung cancer diagnosis during follow-up periods

\begin{tabular}{|c|c|c|c|c|}
\hline Characteristics & All patients & $\begin{array}{l}\text { Patients with lung } \\
\text { cancer }\end{array}$ & $\begin{array}{l}\text { Patients without lung } \\
\text { cancer }\end{array}$ & p-value \\
\hline Patients & 632 & 70 & 562 & \\
\hline Age years & $69.5 \pm 8.5$ & $66.8 \pm 7.9$ & $69.8 \pm 8.5$ & 0.006 \\
\hline Males \% & 76.4 & 94.3 & 74.2 & $<0.001$ \\
\hline BMI $\mathrm{kg} \cdot \mathrm{m}^{-2}$ & $23.2 \pm 3.1$ & $23.2 \pm 2.9$ & $23.2 \pm 3.1$ & 0.996 \\
\hline $\begin{array}{l}\text { Smoking exposure } \\
\text { pack-years }\end{array}$ & $35.0(0-141)$ & $46.4(0.75-120)$ & $31.0(0-141)$ & $<0.001$ \\
\hline Smokers \% & 76.4 & 100 & 73.5 & $<0.001$ \\
\hline Emphysema \% & 29.7 & 60.0 & 26.0 & $<0.001$ \\
\hline FVC $\%$ pred & $76.2 \pm 20.2$ & $89.2 \pm 16.9$ & $75.1 \pm 20.1$ & $<0.001$ \\
\hline FEV $1 / F V C \%$ & $80.3 \pm 10.8$ & $74.1 \pm 9.4$ & $80.9 \pm 10.7$ & $<0.001$ \\
\hline D.co \% pred & $76.4 \pm 23.5$ & $74.9 \pm 26.9$ & $76.6 \pm 23.2$ & 0.517 \\
\hline $\mathrm{PaO}_{2} \mathrm{mmHg}$ & $74.0 \pm 15.1$ & $77.3 \pm 12.2$ & $73.5 \pm 15.4$ & 0.194 \\
\hline ESR $\mathrm{mm} \cdot \mathrm{h}^{-1}$ & $34.0(2-138)$ & $36.5(5-120)$ & $34.0(2-138)$ & 0.665 \\
\hline CRP $\mathrm{mg} \cdot \mathrm{dL}^{-1}$ & $0.24(0.00-50.68)$ & $0.29(0.00-15.11)$ & $0.23(0.00-50.68)$ & 0.819 \\
\hline Albumin $\mathrm{g} \cdot \mathrm{dL}^{-1}$ & $4.0 \pm 0.5$ & $4.0 \pm 0.4$ & $4.0 \pm 0.5$ & 0.763 \\
\hline $\mathrm{KL}-6 \mathrm{U} \cdot \mathrm{mL}^{-1}$ & 762.0 (149-9705) & $649.5(347-2454)$ & 775.0 (149-9705) & 0.078 \\
\hline
\end{tabular}

Data are presented as mean \pm SD or median (range), unless otherwise stated. BMI: body mass index; FVC: forced vital capacity; FEV1: forced expiratory volume in $1 \mathrm{~s}$; DLCO: diffusing capacity of the lung for carbon monoxide; $\mathrm{PaO}_{2}$ : arterial oxygen tension; ESR: erythrocyte sedimentation rate; $\mathrm{CRP}$ : C-reactive protein; $\mathrm{KL}$ : Krebs von der Lungen. $\mathrm{p}$-values were calculated in relation to with or without lung cancer diagnosis. 
FIGURE 1 Kaplan-Meier curve for the time until the development of lung cancer in patients with idiopathic pulmonary fibrosis. The 5- and 10-year cumulative lung cancer development rates were $12.2 \%$ and $23.3 \%$, respectively. The incidence density of lung cancer development was 25.2 cases per 1000 person-years.

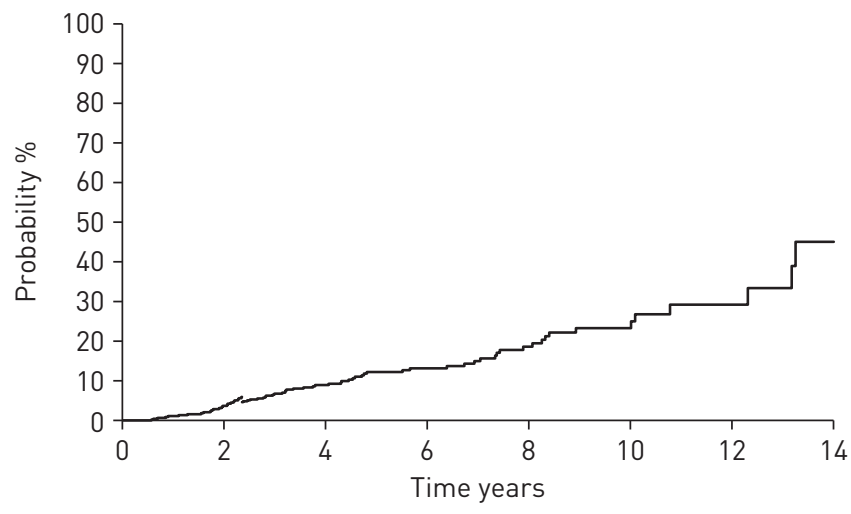

(75.7\%) patients (table 2 and figure 2). LC was diagnosed by regular follow-up radiology in $44(62.9 \%)$ patients and by symptoms in $26(37.1 \%)$ patients. LC stagings were stage I, II, III and IV in $22(31.4 \%), 7$ (10.0\%), $20(28.6 \%)$ and $21(30.0 \%)$ patients, respectively.

\section{Risk factors for LC development}

Univariate analysis indicated that being male, pack-years of smoking, emphysema and FVC \% predicted $\geqslant 80 \%$ were factors associated with LC development (table 3). In a multivariate Cox proportional hazard model, pack-years of smoking $\geqslant 35$ and emphysema were associated with LC development (table 4).

\section{Treatments of LC according to LC staging}

LC treatment according to staging is reported in table 5. Of 22 patients with stage I, 14 (63.6\%) patients underwent operation, and 8 (36.4) received only best supportive care. Of 7 patients with stage II, only 2 (28.6\%) were operated. Of 21 patients with stage IV, 16 (76.2\%) received only best supportive care. Only one patient received radiotherapy.

\section{TABLE 2 Lung cancer that developed during follow-up periods in 70 patients with idiopathic}

\section{pulmonary fibrosis}

\section{Patients}

Age years mean \pm sD

$71.7 \pm 7.8$

Histological type

Squamous cell carcinoma

$21(30.0 \%)$

Adenocarcinoma

$14(20.0 \%)$

Small cell carcinoma

$14(20.0 \%)$

Unclassified nonsmall cell lung cancer

$15(21.4 \%)$

Large cell carcinoma

$2(2.9 \%)$

Others

$4(5.7 \%)$

\section{Performance status}

0

$35(50.0 \%)$

1

2

3

4

\section{Location}

Central

Peripheral

$17(24.3 \%)$

$9(12.9 \%)$

$6(8.6 \%)$

$3(4.3 \%)$

Upper lobes

$12(17.1 \%)$

Middle lobes

$58(82.9 \%)$

Lower lobes

$33(47.1 \%)$

Adjacent to usual interstitial pneumonia

$34(48.6 \%)$

Diagnosis

Incidental findings $\quad 44(62.9 \%)$

Symptoms

Data are presented as $\mathrm{n}(\%)$, unless otherwise stated. 


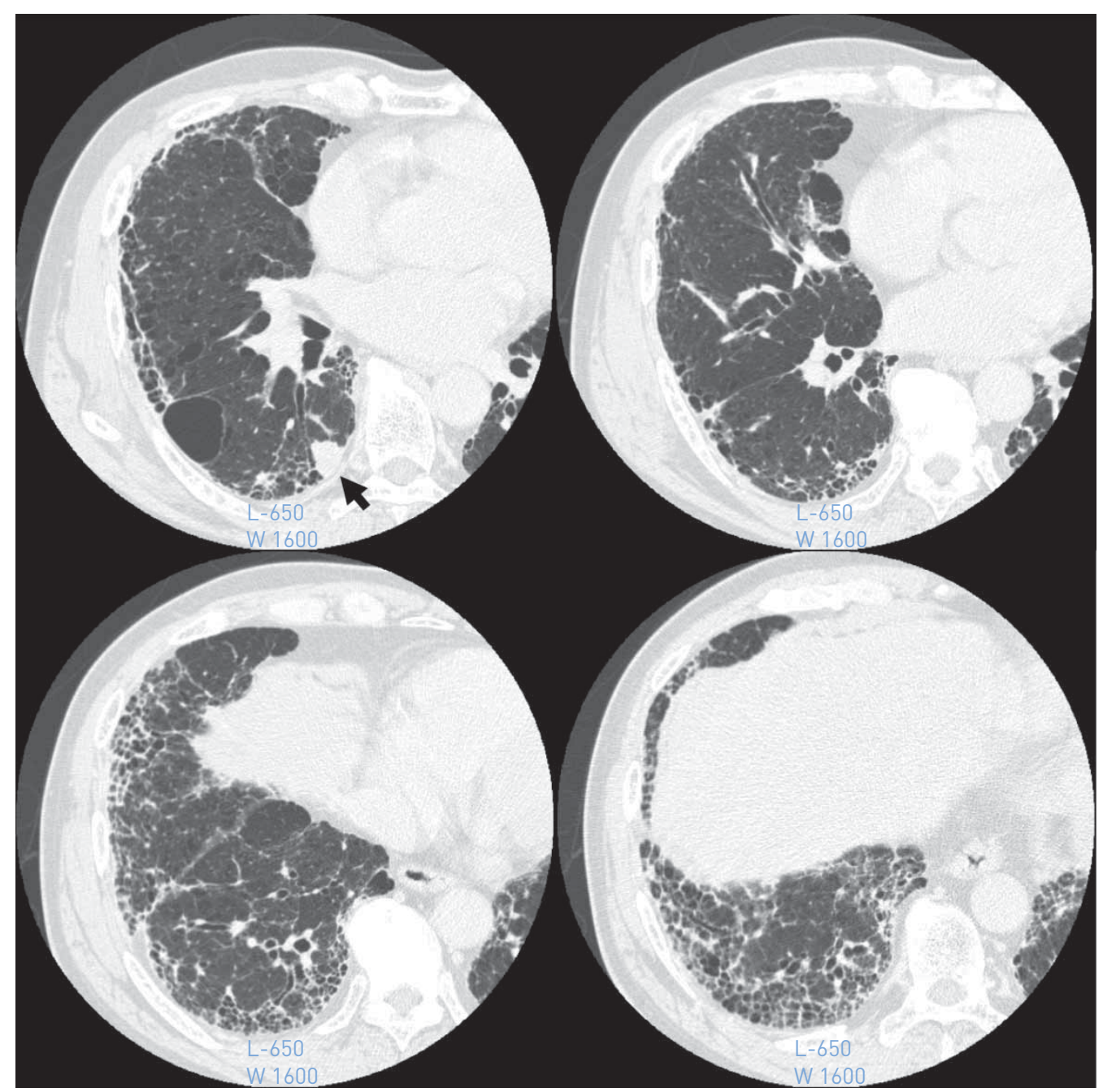

FIGURE 2 High-resolution computed tomography image showing a peripheral right lower lobe mass (arrow) and a usual interstitial pneumonia that exists around the mass to bottom of the lung.

Mortality in IPF patients who did not develop LC or developed LC during follow-up

The respective 5- and 10-year all-cause mortality rates in patients who did not develop LC were $40.4 \%$ and $66.4 \%$ versus $46.9 \%$ and $76.7 \%$ in those who developed LC $(p=0.262)$ (figure 3 ).

\section{Mortality after LC development}

The 1-, 3- and 5-year all-cause mortality rates after LC diagnosis were 53.5\%, 78.6\% and 92.9\%, respectively (figure 4 ).

\section{Discussion}

This long-term longitudinal study of a large cohort of patients with IPF resulted in four important findings. First, the incidence density of LC development in patients with IPF was 25.2 cases per 1000 person-years. Second, the most frequent type was squamous cell carcinoma (30\%), and the majority developed LC in the peripheral lung (82.9\%) and adjacent to UIP (75.7\%). Third, pack-years of smoking and coexisting emphysema were associated with LC development. Fourth, the 1-year all-cause mortality rate after LC diagnosis was high (53.5\%).

The incidence rate of LC in Japan in 2007 was reported to be 1.48 per 1000 person-years [21]. The incidence of LC in patients with IPF is reported to be $11.2-36$ cases per 1000 person-years [7, 19]. The incidence of 25.1 cases per 1000 person-years in the present study was nearly equal to the results from previous studies. TOMASSETTI et al. [20] reported that 23 patients with LC and IPF were more frequently smokers, with combined pulmonary fibrosis and emphysema (52\% versus 32\%), than 158 patients with 


\section{TABLE 3 Univariate Cox regression analysis exploring factors associated with lung cancer} diagnosis in idiopathic pulmonary fibrosis patients

\begin{tabular}{|c|c|c|}
\hline Parameter & $\operatorname{HR}(95 \% \mathrm{CI})$ & p-value \\
\hline \multicolumn{3}{|l|}{ Age years } \\
\hline$<60$ & Ref. & \\
\hline$\geqslant 60$ & $1.402(0.714-2.755)$ & 0.326 \\
\hline \multicolumn{3}{|l|}{ Sex } \\
\hline Female & Ref. & \\
\hline Male & $4.809(1.752-13.199)$ & 0.002 \\
\hline \multicolumn{3}{|l|}{ BMI $\mathrm{kg} \cdot \mathrm{m}^{-2}$} \\
\hline$\geqslant 25$ & Ref. & \\
\hline$\geqslant 18.5-<25$ & $1.258(0.732-2.162)$ & 0.407 \\
\hline$<18.5$ & $0.942(0.218-4.083)$ & 0.937 \\
\hline Unknown & $1.854(0.246-13.954)$ & 0.549 \\
\hline \multicolumn{3}{|c|}{ Smoking history } \\
\hline None & Ref. & \\
\hline Smoker & $>999.999(0.000--)$ & 0.985 \\
\hline \multicolumn{3}{|c|}{ Smoking exposure pack-years } \\
\hline$<35$ & Ref. & \\
\hline$\geqslant 35$ & $3.053(1.747-5.334)$ & $<0.001$ \\
\hline \multicolumn{3}{|l|}{ Emphysema } \\
\hline None & Ref. & \\
\hline Present & $2.944(1.823-4.753)$ & $<0.001$ \\
\hline \multicolumn{3}{|l|}{ FVC $\%$ pred } \\
\hline$\geqslant 80$ & Ref. & \\
\hline$<80$ & $0.449(0.212-0.952)$ & 0.037 \\
\hline Unknown & $1.639(0.991-2.710)$ & 0.054 \\
\hline \multicolumn{3}{|l|}{ FEV $1 /$ FVC $\%$} \\
\hline$\geqslant 70$ & Ref. & \\
\hline$<70$ & $1.877(0.963-3.656)$ & 0.064 \\
\hline Unknown & $2.330(1.382-3.926)$ & 0.001 \\
\hline \multicolumn{3}{|l|}{ D.co $\%$ pred } \\
\hline$\geqslant 80$ & Ref. & \\
\hline$<80$ & $2.179(0.990-4.800)$ & 0.053 \\
\hline Unknown & $2.574(1.250-5.305)$ & 0.010 \\
\hline \multicolumn{3}{|l|}{$\mathrm{PaO}_{2} \mathrm{mmHg}$} \\
\hline$\geqslant 70$ & Ref. & \\
\hline$<70$ & $1.421(0.628-3.216)$ & 0.399 \\
\hline Unknown & $0.850(0.504-1.433)$ & 0.542 \\
\hline \multicolumn{3}{|l|}{ ESR $\mathrm{mm} \cdot \mathrm{h}^{-1}$} \\
\hline$<35$ & Ref. & \\
\hline$\geqslant 35$ & $1.673(0.946-2.959)$ & 0.077 \\
\hline Unknown & $1.391(0.774-2.501)$ & 0.27 \\
\hline \multicolumn{3}{|l|}{ CRP $\mathrm{mg} \cdot \mathrm{dL}^{-1}$} \\
\hline$<0.3$ & Ref. & \\
\hline$\geqslant 0.3$ & $1.217(0.742-1.994)$ & 0.437 \\
\hline Unknown & $0.983(0.427-2.266)$ & 0.968 \\
\hline \multicolumn{3}{|c|}{ Albumin $\mathrm{g} \cdot \mathrm{dL}^{-1}$} \\
\hline$\geqslant 3.5$ & Ref. & \\
\hline$<3.5$ & $2.047(0.910-4.601)$ & 0.083 \\
\hline Unknown & $0.864(0.521-1.432)$ & 0.571 \\
\hline \multicolumn{3}{|l|}{$\mathrm{KL}-6 \mathrm{U} \cdot \mathrm{mL}^{-1}$} \\
\hline$<500$ & Ref. & \\
\hline$\geqslant 500$ & $1.092(0.493-2.420)$ & 0.829 \\
\hline Unknown & $2.041(0.985-4.227)$ & 0.055 \\
\hline \multicolumn{3}{|c|}{$\begin{array}{l}\text { HR: hazard ratio; BMI: body mass index; FVC: forced vital capacity; FEV1: forced expiratory volume in } 1 \mathrm{~s} \text {; } \\
\text { DLCo: diffusing capacity of the lung for carbon monoxide; } \mathrm{PaO}_{2} \text { : arterial oxygen tension; ESR: erythrocyte } \\
\text { sedimentation rate; CRP: C-reactive protein; KL: Krebs von der Lungen. }\end{array}$} \\
\hline
\end{tabular}

IPF only. However, because this study included 7 patients whose LC was diagnosed at the same time as IPF diagnosis, emphysema may not be predictive of the risk of developing LC at the initial diagnosis of IPF. In the present study, in a multivariate Cox proportional hazard model, pack-years of smoking $\geqslant 35$ 
TABLE 4 Multivariate Cox regression analysis exploring factors associated with lung cancer diagnosis in idiopathic pulmonary fibrosis patients

\begin{tabular}{lcc} 
Parameter & HR $(95 \% \mathrm{Cl})$ & p-value \\
$\begin{array}{l}\text { Smoking exposure pack-years } \\
<35\end{array}$ & Ref. & \\
$\quad \geqslant 35$ & $2.354(1.278-4.339)$ & 0.006 \\
$\begin{array}{l}\text { Emphysema } \\
\quad \text { None }\end{array}$ & Ref. & \\
$\quad$ Present & $2.066(1.220-3.498)$ & 0.007 \\
HR: hazard ratio. & & \\
\hline
\end{tabular}

and emphysema were associated with LC development. Similarly, pack-years of smoking and emphysema were reported to be independently associated with LC development in COPD patients [22].

There are many possible underlying mechanisms linking LC and IPF. Epigenetic and genetic alterations, abnormal expression of microRNAs (miRNAs), cellular and molecular aberrances such as an altered response to regulatory signals, delayed apoptosis or reduced cell-to-cell communication, along with the activation of specific signalling transduction pathways, are all features that characterise the pathogenesis of both IPF and LC $[23,24]$. Genetic analysis has revealed that deleterious mutations in surfactant protein A1 or A2 cause familial idiopathic interstitial pneumonia and lung cancer [25-27].

TOMASSETTI et al. [20] reported that survival in patients with IPF with LC was significantly worse than in patients with IPF without LC (time 0 is diagnosis of IPF for both groups). This study included 181 patients with IPF, and, of these patients, 23 developed LC. Among the 23 patients with LC and IPF, 7 (30\%) were diagnosed as having LC at the same time of IPF diagnosis and the other 16 patients $(70 \%)$ developed LC after diagnosis of IPF. OzAWA et al. [18] and HyldgaARD et al. [19] studied 103 and 121 IPF patients without LC at their initial diagnoses, respectively. A total of 21 and 6 patients with IPF developed LC during the observation period, respectively. There were no significant differences in survival between IPF-alone and IPF-LC patients (time 0 is diagnosis of IPF). As in the OzAWA et al. and HyldgaARD et al. studies, our study did not include IPF patients simultaneously having LC at IPF diagnosis, and the survival of patients who developed and did not develop LC was not so different.

Several studies have reported that pulmonary morbidity and mortality are substantially higher, and outcomes are much poorer, after pulmonary resection for LC among patients with IPF than among patients without IPF [28-31]. KREUTER et al. [17] reported the treatment and outcome of 42 patients with IPF and LC. Of the 42 patients, $12(28.6 \%)$ patients underwent surgery, 11 (26.2\%) radiotherapy, 6 (14.3\%) radio-chemotherapy, $10(23.8 \%)$ chemotherapy and 4 (9.5\%) best supportive care. Therapy-associated toxicities were observed in $55 \%$ of the patients, the 30 day mortality among the operated patients was 25\%, 4 (24\%) out of 17 irradiated patients developed radiation-induced pneumonitis, and $63 \%$ of patients with chemotherapy developed chemotherapy-related toxicity. They reported that, despite the high incidence of LC therapy-related complications, a significant survival impact was not detected. KHAN et al. [32] reported the treatment and outcome of 34 patients with IPF and LC. They reported that therapeutic interventions made no significant difference in the overall poor long-term survival of these patients, regardless of the stage of cancer or severity of IPF. KenMoTsu et al. [33] investigated the risk of exacerbation of interstitial lung disease for patients with LC with interstitial lung disease. Patients with UIP pattern developed cytotoxic chemotherapy-related exacerbation of interstitial

TABLE 5 Lung cancer treatment according to clinical staging

\begin{tabular}{lcccc} 
Treatment & \multicolumn{3}{c}{ Stage } \\
\cline { 2 - 5 } & I (n=22) & II $(\mathbf{n = 7 )}$ & III (n=20) & IV (n=21) \\
\hline Surgery & $14(63.6 \%)$ & $2(28.6 \%)$ & $4(20.0 \%)$ & $1(4.8 \%)$ \\
Chemotherapy & $0(0.0 \%)$ & $2(28.6 \%)$ & $8(40.0 \%)$ & $4(19.0 \%)$ \\
Radiotherapy & $0(0.0 \%)$ & $0(0.0 \%)$ & $1(5.0 \%)$ & $0(0.0 \%)$ \\
Best supportive care & $8(36.4 \%)$ & $3(42.9 \%)$ & $7(35.0 \%)$ & $16(76.2 \%)$
\end{tabular}




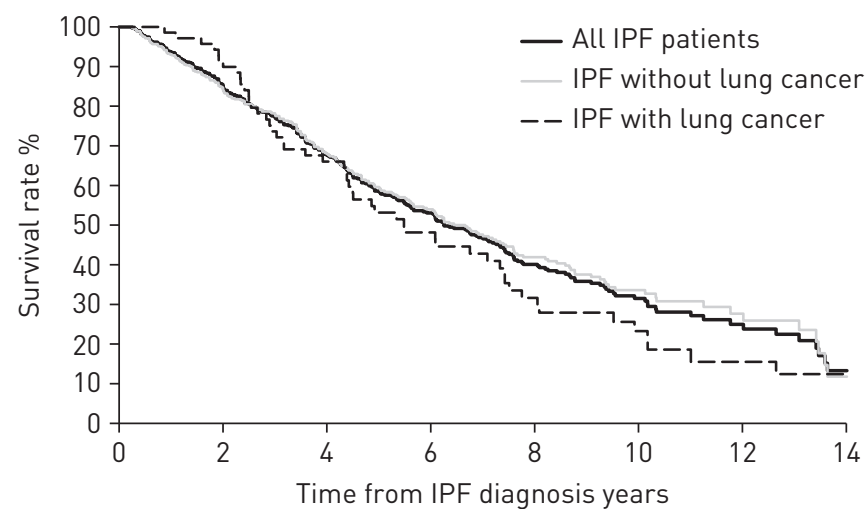

FIGURE 3 Kaplan-Meier survival curves of all-cause mortality in patients with idiopathic pulmonary fibrosis (IPF). The 5- and 10-year mortality rates of all patients, patients who did not develop lung cancer and patients who developed lung cancer were $41.4 \%$ and $68.5 \%, 40.4 \%$ and $66.4 \%$, and $46.9 \%$ and $76.7 \%$, respectively. A log-rank test showed that the difference between survival curves of patients with or without lung cancer diagnosis was not significant ( $p=0.262)$.

lung disease more frequently than those with non-UIP pattern $(30 \%$ versus $8 \%, \mathrm{p}=0.005)$. The incidence of grade 5 pulmonary toxicities was $9 \%$ in patients with UIP pattern, compared with $3 \%$ in those with non-UIP pattern. In the present study, overall, $34(48.6 \%)$ of the 70 patients could not receive standard-of-care treatment for LC and only received best supportive care. In our study, 2 (9.5\%) of the 21 operated patients and 1 (7.1\%) of the 14 patients who received chemotherapy developed acute exacerbation. Two of these patients died.

The papers reporting survival among IPF patients with LC were limited by small sample sizes. Mean survival time after LC diagnosis in 24 and 42 patients with IPF and LC was reported to be 1.6 and 1.7 years, respectively $[15,17]$. The median survival time after LC diagnosis in 21 patients with IPF and LC was reported to be 1.1 years [18]. In the present study, the 1-year all-cause mortality rate after LC diagnosis was $53.5 \%$, showing overall poor survival, like previous studies.

One limitation of this study is that it is retrospective, so some clinical and laboratory findings were not available. Second, our conclusions are limited because this study is a single-centre review. Third, the true cumulative incidence of LC may be underestimated because routine screening for LC was lacking. Fourth, there is a problem of censored cases with competing risk events. In our study, the age at IPF diagnosis of the group with LC development was younger than that of the group without LC development (medians of 67.5 years and 71.0 years, respectively) and FVC \% at IPF diagnosis of the group with LC development was higher than that of the group without LC development (median of $91.3 \%$ and $74.7 \%$, respectively). Elderly patients with depressed pulmonary function have a poor prognosis and, accordingly, it is possible that they will die before developing LC. When patients have poor prognostic factors, survival time tends to be shortened, and poor prognostic factors may reduce the risk of developing LC due to patient death before the onset of LC. The method to solve the problem of censoring by competing risk event is to constitute an event called "lung cancer development or death" using "lung cancer development" and "death", and to analyse the occurrence and risk factors of the event. This analytical method enables the

FIGURE 4 Kaplan-Meier survival curves of all-cause mortality in patients with idiopathic pulmonary fibrosis after lung cancer development. The 1-, 3- and 5-year all-cause mortality rates after lung cancer diagnosis were $53.5 \%$, $78.6 \%$ and $92.9 \%$, respectively.

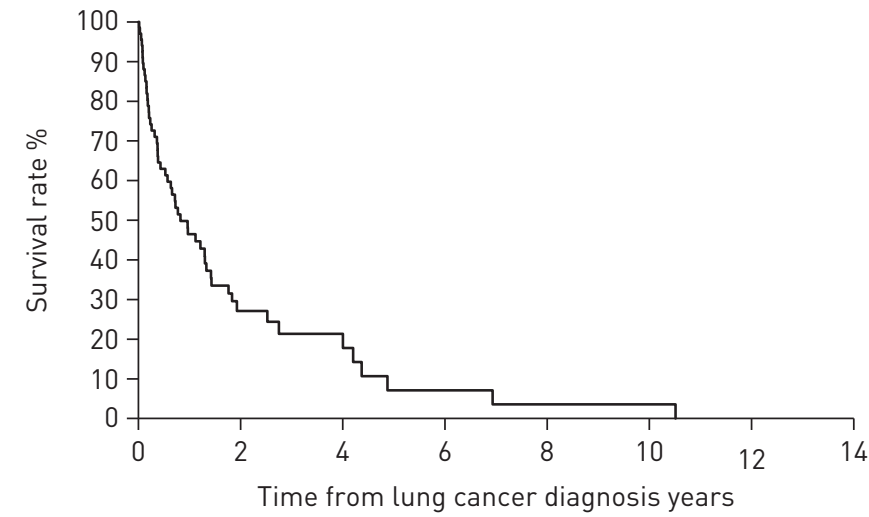


search for risk factors for which "lung cancer development or death" is high. However, this analytical method does not allow for the search of the pure risk factor of LC development. After discussing this with a statistician, we determined that it would be better to adopt Cox regression analysis of "lung cancer-free time".

In conclusion, the incidence density of LC is high in IPF patients and occurs more frequently in patients with a smoking history of pack-years of smoking $\geqslant 35$ and coexisting emphysema. The majority of LCs develop adjacent to UIP. Knowledge of these factors may help direct efforts for the early detection of LC and disease management.

\section{Acknowledgements}

We thank Tsutomu Yanagisawa and Kazuyoshi Kurashima of the Department of Respiratory Medicine, Saitama Cardiovascular and Respiratory Center, for their handling of the diagnosis and treatment of the patients with rheumatoid arthritis-associated UIP.

\section{References}

1 Raghu G, Collard HR, Egan JJ, et al. An official ATS/ERS/JRS/ALAT statement: idiopathic pulmonary fibrosis: evidence-based guidelines for diagnosis and management. Am J Respir Crit Care Med 2011; 183: 788-824.

2 Travis WD, Costabel U, Hansell DM, et al. An official American Thoracic Society/European Respiratory Society statement: update of the international multidisciplinary classification of the idiopathic interstitial pneumonias. Am J Respir Crit Care Med 2013; 188: 733-748.

3 Panos RJ, Mortenson RL, Niccoli SA, et al. Clinical deterioration in patients with idiopathic pulmonary fibrosis: causes and assessment. Am J Med 1990; 88: 396-404.

4 Raghu G, Amatto VC, Behr J, et al. Comorbidities in idiopathic pulmonary fibrosis patients: a systematic literature review. Eur Respir J 2015; 46: 1113-1130.

5 Turner-Warwick M, Lebowitz M, Burrows B, et al. Cryptogenic fibrosing alveolitis and lung cancer. Thorax 1980; 35: 496-499.

6 Hubbard R, Venn A, Lewis S, et al. Lung cancer and cryptogenic fibrosing alveolitis. A population-based cohort study. Am J Respir Crit Care Med 2000; 161: 5-8.

7 Le Jeune I, Gribbin J, West J, et al. The incidence of cancer in patients with idiopathic pulmonary fibrosis and sarcoidosis in the UK. Respir Med 2007; 101: 2534-2540.

8 Harris JM, Johnston ID, Rudd R, et al. Cryptogenic fibrosing alveolitis and lung cancer: the BTS study. Thorax 2010; 65: 70-76.

9 Collard HR, Ward AJ, Lanes S, et al. Burden of illness in idiopathic pulmonary fibrosis. J Med Econ 2012; 15: 829-835.

10 Natsuizaka M, Chiba H, Kuronuma K, et al. Epidemiologic survey of Japanese patients with idiopathic pulmonary fibrosis and investigation of ethnic differences. Am J Respir Crit Care Med 2014; 190: 773-779.

11 Nagai A, Chiyotani A, Nakadate T, et al. Lung cancer in patients with idiopathic pulmonary fibrosis. Tohoku Exp Med 1992; 167: 231-237.

12 Lee HJ, Im JG, Ahn JM, et al. Lung cancer in patients with idiopathic pulmonary fibrosis: CT findings. J Comput Assist Tomogr 1996; 20: 979-982.

13 Hironaka M, Fukayama M. Pulmonary fibrosis and lung carcinoma: a comparative study of metaplastic epithelia in honeycombed areas of usual interstitial pneumonia with or without lung carcinoma. Pathol Int 1999; 49: 1060-1066.

14 Park J, Kim DS, Shim TS, et al. Lung cancer in patients with idiopathic pulmonary fibrosis. Eur Respir J 2001; 17: $1216-1219$.

15 Aubry MC, Myers JL, Douglas WW, et al. Primary pulmonary carcinoma in patients with idiopathic pulmonary fibrosis. Mayo Clin Proc 2002; 77: 763-770.

16 Araki T, Katsura H, Sawabe M, et al. A clinical study of idiopathic pulmonary fibrosis based on autopsy studies in elderly patients. Intern Med 2003; 42: 483-489.

17 Kreuter M, Ehlers-Tenenbaum S, Schaaf M, et al. Treatment and outcome of lung cancer in idiopathic interstitial pneumonias. Sarcoidosis Vasc Diffuse Lung Dis 2015; 31: 266-274.

18 Ozawa Y, Suda T, Naito T, et al. Cumulative incidence of and predictive factors for lung cancer in IPF. Respirology 2009; 14: 723-728.

19 Hyldgaard C, Hilberg O, Bendstrup E. How does comorbidity influence survival in idiopathic pulmonary fibrosis? Respir Med 2014; 108: 647-653.

20 Tomassetti S, Gurioli C, Ryu JH, et al. The impact of lung cancer on survival of idiopathic pulmonary fibrosis. Chest 2015; 147: 157-164.

21 Matsuda A, Matsuda T, Shibata A, et al. Cancer incidence and incidence rates in Japan in 2007: a study of 21 population-based cancer registries for the monitoring of cancer incidence in Japan (MCIJ) project. Jpn J Clin Oncol 2013; 43: 328-336.

22 de-Torres JP, Wilson DO, Sanchez-Salcedo P, et al. Lung cancer in patients with chronic obstructive pulmonary disease. Development and validation of the COPD Lung Cancer Screening Score. Am J Respir Crit Care Med 2015; 191: 285-291.

23 Vancheri C, Failla M, Crimi N, et al. Idiopathic pulmonary fibrosis: a disease with similarities and links to cancer biology. Eur Respir J 2010; 35: 496-504.

24 Vancheri C. Idiopathic pulmonary fibrosis and cancer: do they really look similar? BMC Med 2015; 13: 220.

25 Wang Y, Kuan PJ, Xing C, et al. Genetic defects in surfactant protein A2 are associated with pulmonary fibrosis and lung cancer. Am J Hum Genet 2009; 84: 52-59.

26 van Moorsel CH, Ten Klooster L, van Oosterhout MF, et al. SFTPA2 Mutations in familial and sporadic idiopathic interstitial pneumonia. Am J Respir Crit Care Med 2015; 192: 1249-1252. 
27 Nathan N, Giraud V, Picard C, et al. Germline SFTPA1 mutation in familial idiopathic interstitial pneumonia and lung cancer. Hum Mol Genet 2016; 25: 1457-1467.

28 Kawasaki H, Nagai K, Yoshida J, et al. Postoperative morbidity, mortality, and survival in lung cancer associated with idiopathic pulmonary fibrosis. J Surg Oncol 2002; 81: 33-37.

29 Chiyo M, Sekine Y, Iwata T, et al. Impact of interstitial lung disease on surgical morbidity and mortality for lung cancer: analyses of short-term and long-term outcomes. J Thorac Cardiovasc Surg 2003; 126: 1141-1146.

30 Watanabe A, Higami T, Ohori S, et al. Is lung cancer resection indicated in patients with idiopathic pulmonary fibrosis? J Thorac Cardiovasc Surg 2008; 136: 1357-1363.

31 Saito Y, Kawai Y, Takahashi N, et al. Survival after surgery for pathologic stage IA non-small cell lung cancer associated with idiopathic pulmonary fibrosis. Ann Thorac Surg 2011; 92: 1812-1817.

32 Khan KA, Kennedy MP, Moore E, et al. Radiological characteristics, histological features and clinical outcomes of lung cancer patients with coexistent idiopathic pulmonary fibrosis. Lung 2015; 193: 71-77.

33 Kenmotsu H, Naito T, Kimura M, et al. The risk of cytotoxic chemotherapy-related exacerbation of interstitial lung disease with lung cancer. J Thorac Oncol 2011; 6: 1242-1246. 